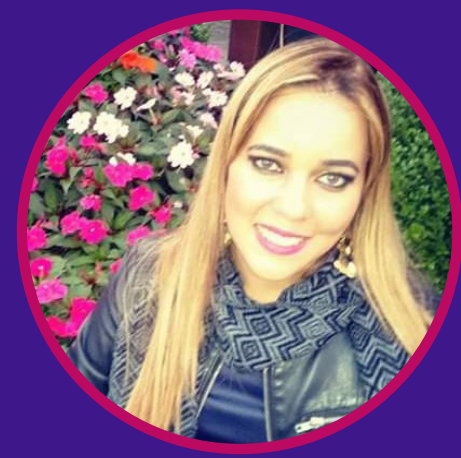

\title{
Comprensión del contexto fotográfico mediante el uso del Modelo de Lectura para la indización fotográfica basada en el Método complejo y las funciones primarias de la imagen
}
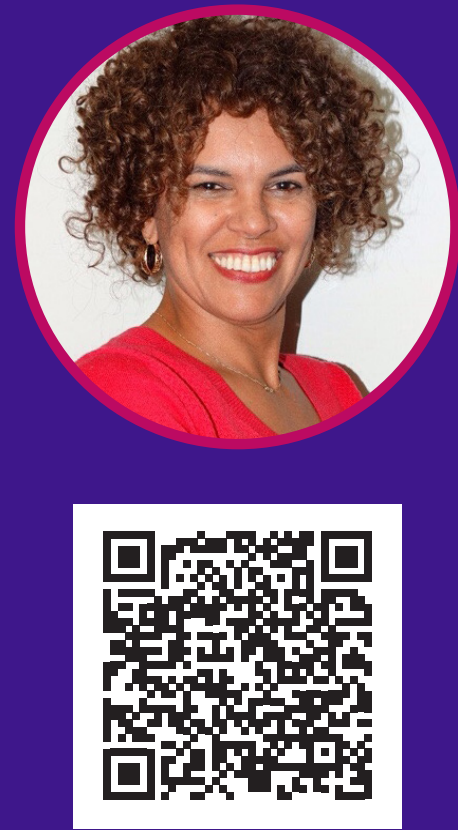

Understanding the photographical context using the Reading model based on the Complex Method and the primary functions of images

Grad. Gislene Rodrigues da Silva

Universidade Federal de

Minas Gerais

gislenerds@gmail.com

Recibido: 16 de enero de 2020.

Aceptado: 16 de marzo de 2020.
Dra. Célia da Consolação Dias

Universidade Federal de

Minas Gerais

celiadias@gmail.com

Received: January 16th 2020.

Accepted: March 16th 2020.

cc) (i) (ㅇ) Esta obra está bajo una licencia internacional Creative

EY NC ND Commons Atribución-NoComercial-SinDerivadas 4.0.

Cómo citar: Rodrigues da Silva, G. ., \& da Consolação Dias, C. . (2020). Comprensión del contexto fotográfico mediante el uso del Modelo de Lectura para la indización fotográfica basada en el Método complejo y las funciones primarias de la imagen. $R P C$, (1), 115-125. https://doi.org/10.21555/rpc.v0i1.2324

Revista Panamericana de Comunicación, Año 2, N. 1, enero-junio 2020, pp. 115-125.

\section{RESUMEN}

Esta investigación tiene como objetivo discutir la importancia de comprender el contexto de la fotografía en el momento de la indización. Esta discusión se basó en la aplicación de la Matriz 1 y la Matriz 2 del Modelo de Lectura de Indización de Fotografías desarrollado en base al Método Complejo y las Funciones Primarias de la Imagen. Este modelo fue aplicado por dos grupos de estudiantes del curso de Biblioteconomía de la Universidad Federal de Minas Gerais, Brasil, utilizando Matriz 1 y Matriz 2 y también por un usuario externo a los grupos que trabajaron con Matriz 2.

La investigación es de naturaleza exploratoria y aplicada. La muestra trabajada fue seleccionada convenientemente, está formada por dos fotografías que retratan temas actuales. Los participantes recibieron instrucciones de usar indización libre. Como resultado, se observó que al buscar información sobre el contexto 
de las fotografías, los profesionales de la información tenían más subsidios para la selección de palabras- clave al indexar usando Matriz 1 . El usuario externo que usaba la Matriz 2 directamente y no buscó información sobre el contexto de las fotografías analizadas, identificó palabras clave relacionadas con el contenido que pudo ver e interpretar en la foto.

Palabras-clave: Método Complejo, Funciones Primarias de la Imagen, Indización de fotos

\section{ABSTRACT}

This study discusses the importance of understanding the context of a given photograph for effective indexing. It is based on the application of Matrix 1 and Matrix 2 of the Photograph Indexation Reading Model that was de- veloped following the Complex Method and the primary functions of images. The model was applied by two groups of Library Science students at the Federal University of Minas Gerais, Brazil, using Matrix 1 and Matrix 2, as well as by an external user who only applied Matrix 2 . The research presented in this paper is of an exploratory and applied nature. It analyzes a sample of two photographs that portray contemporary events. Participants were instructed to apply free indexing. It was observed that, when looking for information about the context of the images, information professionals had more resources for selecting key-words when indexing using Matrix 1. On the other hand, the external user who used Matrix 2 directly, without searching for information about context, only identified key-words related to the content that could be seen and interpreted in the photograph.

Keywords: Complex Method, Primary functions of images, Photography indexing

\section{INTRODUCCIÓN}

La fotografía es un tipo de imagen que está cada vez más presente en la vida cotidiana de las personas, especialmente después de la popularización de los dispositivos digitales y los teléfonos móviles que permitieron un mayor acceso y una mayor circulación de este tipo de recurso. Debido a esto, la fotografía, a menudo, se difunde fuera de su contexto de creación, lo que permite a las personas interpretar el objeto fotografiado de varias maneras 0 , incluso, difundirlo fuera de su contexto de creación, debido a su carácter polisémico.

Desde el punto de vista de la organización de la información, indizar una fotografía es un gran desafío para el profesional de la información ya que el proceso de indización también exige la búsqueda de infor- mación sobre su contexto. Este paso requiere el uso de fuentes confiables para apoyar la construcción de información sobre este contexto, que luego será útil para ayudar y dirigir la selección de palabras -clave que mejor representen el contenido de cada fotografía.

Se observó que la representación de la fotografía exige la comprensión de todos los elementos que están vinculados a ella como la verificación de la información transmitida por la foto, la identificación del mensaje contenido o transmitido en la foto, el análisis de las posibilidades de reflexión proporcionadas por la fotografía y también la identificación de la emoción que la foto transmite y puede provocar en las personas.

En consecuencia, el uso del modelo de lectura para la indización de las fotografias basado en el método complejo y las funciones primarias de la imagen que 
propuso Silva (2018) es un modelo de lectura desarrollado en dos niveles. En el primer nivel, el profesional de la información investiga los elementos que permitirán comprender el contexto de la creación de la fotografía utilizando la Matriz 1 para la recopilación de datos. En el segundo nivel, el professional, usando la información recopilada en el primer nivel de lectura, representará el contenido de las fotos usando la Matriz 2.

Por lo tanto, el objetivo de esta investigación fue discutir la necesidad de buscar información para que el profesional entienda el contexto de la creación de fotografías para realizar su indización. Por lo tanto, esta comprensión se puede obtener mediante el uso de este modelo de lectura y, en este estúdio, se aplicó a dos grupos de estudiantes del curso de Biblioteconomía de la Universidad Federal de Minas Gerais (UFMG) a través de la Matriz 1 y la Matriz 2 y aplicación de Matriz 2 a un usuario externo a cada grupo.

\section{REFERENCIAS CONCEPTUALES METODOLÓGICAS}

En esta sección presentaremos el apoyo teórico conceptual y metodológico para el desarrollo del modelo de lectura para la indización de fotografias basado en el método complejo y las funciones primarias de la imagen. La construcción de este modelo tuvo aportes teóricos de la comunicación visual. Estas contribuciones teóricas proporcionan información para comprender la importancia de la relación entre las imágenes y otras fuentes de información con el fin de comprender su contenido. Abril (2007) propone el uso de la expresión «texto visual» para referirse a la imagen, considerando que el término representa mejor esta característica porque amplía la relación que establece con el texto y con otras fuentes de información.

Además, el autor supone la existencia de «redes textuales» y afirma que, por esta razón, siempre hay interacción entre estos recursos. Abril (2007) también enfatiza que los textos visuales también deben ser vistos como formas dinámicas, nunca completamente determinadas, ya que su interpretación varía según el momento de la historia y también según los valores de una cultura.
Català Domènech (2015) está de acuerdo con Abril (2007) al presentar la expresión "Mirada Complexa" en la que afirma que la interpretación de una imagen depende de la relación que el espectador establezca con ella para hacerla compleja. Otro aspecto señalado por el autor muestra que las imágenes no son objetos aislados, ya que, a menudo, puede parecer que son un objeto cerrado pero, cuando se les pregunta, está claro que pueden estar relacionados con otra imagen o, incluso, con textos. Si están disponibles en Internet, esto se vuelve aún más explícito. Con todo esto, el autor reitera que la imagen es parte de un "todo" y, para comprenderlo, es necesario comprender todas estas relaciones.

Las propuestas de Abril (2007) y Català Domènech (2015) sobre la importancia de identificar y comprender textos vinculados a imágenes apoyan la creación del modelo de Indización de Lectura basado en el Método Complejo y las Funciones de Imagen Primaria. El marco teórico que sustentaba el desarrollo de este modelo comprendía el Método Complejo y las Funciones Primarias de la Imagen que utilizaban los principios de comunicación visual propuestos por Català Domènech (2011), como se describe a continuación:

El Método Complejo tiene como objetivo ampliar la interpretación de imágenes a través de tres elementos: Descripción, Ecología e Interpretación de imágenes.

En la Descripción se analiza que la imagen está compuesta y para ello es necesario comprender qué elementos y materiales que la componen y cuáles no están directamente vinculados a su mecanismo representativo, su funcionalidad. Se trata de ir más allá de lo superficial y rastrear el vínculo entre una imagen y otra.

En la Ecología de la imagen es necesario identificar si La imagen se encuentra en un determinado contexto, así como su relación, se nutre y si es consecuencia de ese contexto (ecología). Se refiere a la idea de imagen de red, es decir, imagen multirrelacionada. Esta ecología visual exige una comprensión del conjunto, de entender la multiplicidad de elementos y su relación con el contexto en el que se inserta. Significa comprender si la imagen está relacionada con algún texto o incluso con alguna imagen. Significa comprender esta relación y si se ayuda al interpretar esa imagen. 
Ya en la Interpretación, se busca entender a dónde va la imagen, se busca identificar su significado en el momento de la creación y si ese significado ha cambiado con el tiempo.

Otro marco teórico de Català Domènech (2011) que guió la creación del modelo de lectura lo constituyen las Funciones Primarias de la Imagen. Las Funciones Primarias de la Imagen presentan las modalidades de imágenes existentes para realizar correctamente su proceso de lectura, aprendizaje, comprensión y asimilación visual. Las mismas se componen de Función nformativa, Función comunicativa, Función reflexiva y Función emocional.

La Función informativa comprende imágenes que reproducen algo que alguien quiere informar. Esta función proporciona información sobre un evento o hecho en particular, es decir, presenciar una realidad o encontrar una presencia.

La Función comunicativa denota que la imagen tiene el objetivo de establecer una relación directa con el espectador, en el sentido de transmitir información específica de utilidad inmediata, de inducir una acción, de instruir sobre un tema en particular.

La Función reflexiva se compone de dos tipos: imágenes de pensamiento e imagen autónoma. Las imágenes de pensamiento presentan el punto de vista de quién produjo. Son imágenes que fueron producidas para ser pensadas a partir de ellas. Las imágenes autónomas son las imágenes que presentan un pensamiento independiente de quien las produjo; eso significa que esta reflexión va más allá de las ideas del autor.

La Función emocional se asegura de que todas las imágenes despierten algún tipo de emoción en el espectador. El autor también enfatiza que la forma en que se ve la imagen es decisiva para identificar su aspecto emocional.

A partir de las propuestas de Català Domènech (2011) presentadas anteriormente, el Modelo de Lectura se elaboró creando dos matrices para el registro de información que respaldaban los dos niveles de lectura de las fotografías. En el primer nível, la Matriz 1 se construyó con base en los fundamentos del Método Complejo y la adopción de las preguntas de indización propuestas para hacer el análisis de la fotografía y subsidiar la comprensión de su contexto de creación, la comprensión de su uso y la comprensión de sus formas de interpretación. Todos los datos recopilados y registrados en Matriz 1 son útiles para ayudar a completar Matriz 2.

Matriz 1 - Primer nivel del Modelo de Lectura para la Indización Fotográfica basada en el Método Complejo y las Funciones Primarias de La Imagen

\section{¿De qué está compuesta la imagen? \\ Descripción:}

¿Que nutre la imagen?

Descripción:

\begin{abstract}
¿A dónde va la imagen?
Descripción:
\end{abstract}

Fuente: Elaborada por los autores.

En el segundo nivel, la Matriz 2 se construyó en función de las Funciones Primarias de La Imagen y las preguntas de indización elaboradas a partir de cada función. El registro de datos de esta matriz comprende el segundo nivel de lectura y se realiza utilizando los subsidios de la Matriz 1 para comprender el contenido de la fotografía y definir las palabras clave para la indización.

Matriz 2 - Segundo nivel del Modelo de Lectura para la Indización fotográfica basada en el Método Complejo y las Funciones Primarias de La Imagen

\section{Función informativa}

¿La imagen proporciona información sobre un hecho o evento en particular? ¿Cuál es este hecho o evento que se muestra en la imagen? ¿Qué muestran las imágenes?

Palabras -clave: 


\section{Función comunicativa}

¿Qué comunica la imagen? ¿Qué mensaje transmite la imagen? ¿La imagen induce una acción? ¿La imagen instruye sobre un tema en particular? ¿La imagen ilustra una teoría? ¿La imagen ilustra algún objeto de manera realista?

Palabras- clave:

\section{Función reflexiva}

¿La imagen expone algún pensamiento del autor (fotógrafo)? ¿Cuáles son los pensamientos expuestos por el autor de la imagen? ¿Cuál es la intención del autor de la imagen? ¿Cuál es el posible significado que el espectador (usuario) puede dar a la imagen? ¿Qué reflexiones puede proponer la imagen?

Palabras -clave:

\section{Función emocional}

¿Qué emociones puede despertar la imagen? ¿Qué emoción transmite la imagen? ¿La imagen despierta alguna emoción en el espectador (usuario)? ¿La imagen estimula algún estado mental en el usuario?

Palabras -clave:

Fuente: Elaborada por los autores.

\section{METODOLOGÍA}

Esta investigación se caracteriza por ser cualitativa y exploratoria, ya que busca comprender el uso del modelo de lectura propuesto. Además, puede considerarse aplicado, ya que este modelo desarrollado fue utilizado en la práctica por futuros profesionales de la información y usuarios externos.

De lo expuesto, seleccionamos dos fotografías de diferentes sujetos y fotógrafos famosos para componer la muestra, esta selección se realizó de acuerdo con la conveniencia de la investigación. Estas muestras se llamaron Muestra 1 y Muestra 2, como se muestra en la Tabla 1. La Muestra 1 se refiere a una fotografía viral del fotógrafo holandés Dick Van Duijn, donde capturó el momento exacto en que una ardilla huele la flor para alimentarse. La muestra 2, por otro lado, se refiere a la fotografía de José Medeiros con un registro de un ri- tual secreto de Candomblé en 1957 en Bahía, Brasil. Ilamado el inicio de las hijas de los santos para la revista "O Cruzeiro", que ilustra el título "As noivas dos deuses sanguinários".

Tabla 1. Muestra de la Investigación

\section{MUESTRA FOTOGRAFÍA}

1

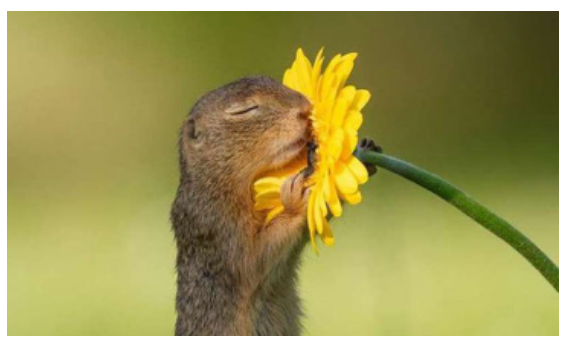

Fuente: G1 (2020).

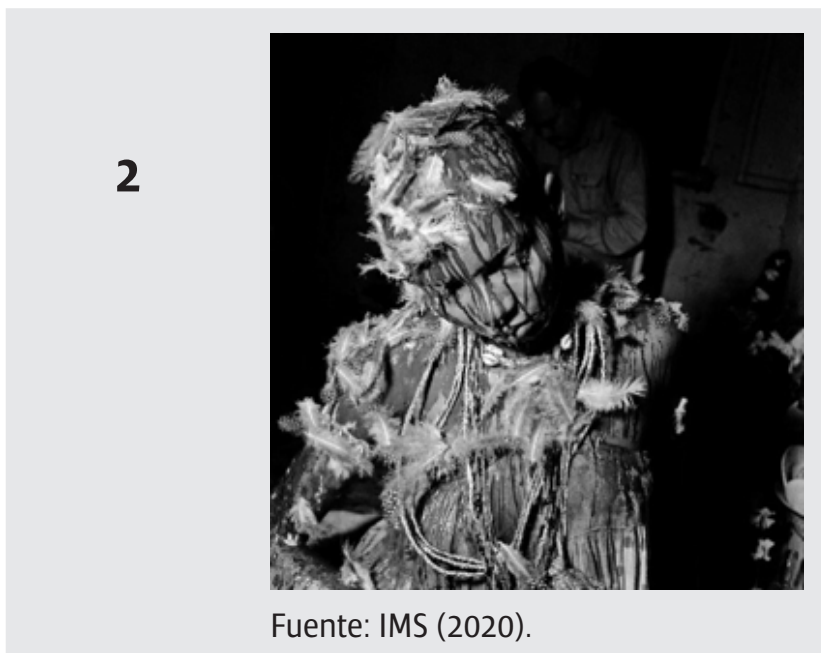

Fuente: Elaborada por los autores.

La parte empírica de la investigación fue la siguiente: la primera parte se realizó con dos grupos de estudiantes del curso de Biblioteconomía, UFMG, Ilamado Grupo 1 y Grupo 2. La segunda parte de la investigación se llevó a cabo dos usuarios externos a cada grupo, Ilamado Usuario 1 y Usuario 2. La división de tareas fue la siguiente: Grupo 1 aplicó el modelo en la Muestra 1 y Grupo 2 en la Muestra 2. Ambos grupos de participantes aplicaron el Modelo de Lectura de Indización de fotos 
usando la Matriz 1 y la Matriz 2. La indización se realizó sin vocabulario controlado. En la segunda parte se le pidió al Grupo 1 que eligiera un usuario y aplicara la Matriz 2 a la Muestra 1. Este usuario se llamó Usuario 1. Al grupo 2 también se le pidió elegir un usuario y aplicar la Matriz 2 en la Muestra 2. Este usuario se llamó Usuario 2. Finalmente, en la tercera parte de la investigacion, se le pidió a cada grupo que analizara la diferencia en la indización realizada por el grupo y la realizada por el usuario.

Por lo tanto, la investigación se dividió en cuatro etapas:

\section{Primera parte:}

» Paso 1: distribución de una fotografía de muestra a cada grupo. Es importante destacar que no se transmitió información previa sobre las fotografías a los participantes.

» Paso 2: solicitud a cada grupo para que revise su fotografía de muestra y siga las instrucciones para usar y registrar la información en la Matriz 1 y la Matriz 2.

\section{Segunda parte:}

» Paso 3: se le pidió a cada grupo que seleccionara un usuario fuera de la clase y aplicara Matriz 2.

\section{Tercera parte:}

» Paso 4: se pidió a cada grupo que analizara la diferencia entre el resultado de la indización realizada por el grupo de estudiantes y el realizado por el usuario externo.

En este sentido, la siguiente sección presentará el resultado de la aplicación de los pasos por parte de estudiantes y usuarios externos.

\section{APLICACIÓN DEL MODELO DE LECTURA PARA LA INDIZACIÓN FOTOGRÁFICA BASADA EN EL MÉTODO COMPLEJO Y LAS FUNCIONES PRIMARIAS DE LA IMAGEN}

Esta sección presenta el resultado de aplicar el Modelo de lectura de indización de fotos para las dos muestras presentadas anteriormente:

\section{Muestra 1:}

Primera parte

Paso 1: Muestra 1 - Grupo 1

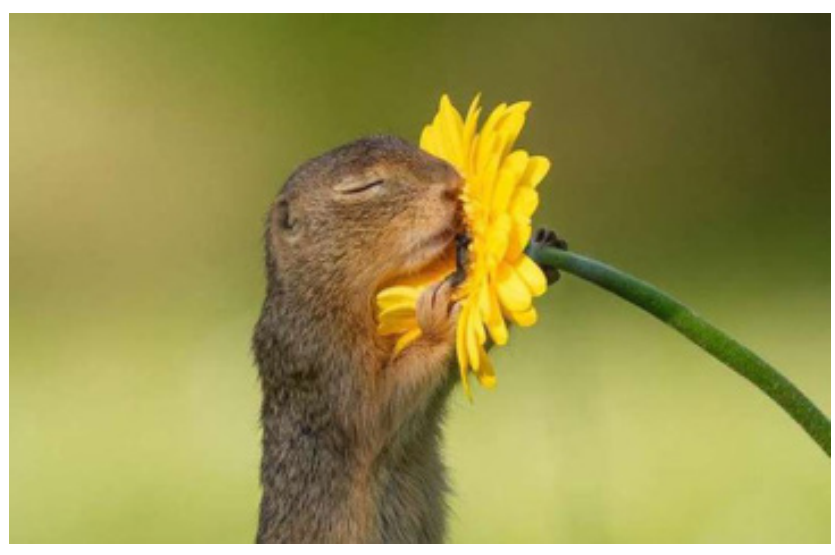

Fuente: G1 (2020).

Paso 2: Aplicar Matriz 1 y Matriz 2 por Grupo 1.

Matriz 1: Primer nivel del Modelo de Lectura para la Indización fotográfica basada en el Método complejo y las Funciones Primarias de La Imagen

\section{¿De qué está compuesta la imagen?}

Descripción:

El fotógrafo holandés Dick van Duijn, Viena, Austria, durante un viaje de verano en junio. Ardilla listada que huele una flor amarilla. Reacciones positivas de los espectadores. Fotógrafo y experto en fotografía de vida salvaje y naturaleza, tiene más fotos con el mismo estilo en tus redes sociales. Se descubrió a través de la investigación del fotógrafo que el animal estaba oliendo la planta para comérselo. 


\section{¿Que nutre la imagen?}

Descripción:

Instagram y Facebook por el fotógrafo Dick van Duijn. Reproducción en Instagram de otros portales de noticias: @newyorkpost @dailymail @dailymirror @foxnews@ thesun @ telegraaf.nl_corriere y sitios de noticias: G1, Gaceta en línea, Catioro reflectante, Ziesel [tipo ardilla]. Fotógrafo y especialista en fotografía de vida salvaje y naturaleza.

\section{¿A dónde va la imagen?}

Descripción:

De los sitios y redes sociales consultados anteriormente se llegó a los siguientes términos: descripción -Ardilla que huele una flor amarilla. Comida. Ziesel [tipo ardilla] que huele una flor. Imágenes de animales. Vida salvaje. ArdiIla. La naturaliza. Flores. Dick van Duijn.

Fuente: Elaborada por los autores.

Matriz 2: Segundo nivel del Modelo de Lectura para la Indización fotográfica basada en el Método Complejo y las Funciones Primarias de La Imagen

\section{Función informativa \\ ¿La imagen proporciona información sobre un hecho o evento en particular? ¿Cuál es este hecho o evento que se muestra en la imagen? ¿Qué muestran las imágenes? \\ Palabras- clave: \\ ARDILLAS. NATURALEZA. VIDA SALVAJE. FLOR AMARI- \\ LLA. SPERMOPHILUS. ZIESEL. ARDILLA QUE HUELE UNA \\ FLOR. VERANO. VIENA. AUSTRIA. VIDA ANIMAL. NATURA- \\ LEZA SALVAJE.}

\section{Función comunicativa}

¿Qué comunica la imagen? ¿Qué mensaje transmite la imagen? ¿La imagen induce una acción? ¿La imagen instruye sobre un tema en particular? ¿La imagen ilustra una teoría? ¿La imagen ilustra algún objeto de manera realista?

Palabras -clave:

VIDA SALVAJE. FOTOS DE VIDA SILVESTRE. ARDILLAS.

FLOR AMARILLA.

\section{Función reflexiva}

¿La imagen expone algún pensamiento del autor (fotógrafo)? ¿Cuáles son los pensamientos expuestos por el autor de la imagen? ¿Cuál es la intención del autor de la imagen? ¿Cuál es el posible significado que el espectador (usuario) puede dar a la imagen? ¿Qué reflexiones puede proponer la imagen?

Palabras- clave:

NATURALEZA. ARMONÍA. DELICADEZA. SUAVIDAD. AROMA. BELLEZA.

\section{Función emocional}

¿Qué emociones puede despertar la imagen? ¿Qué emoción transmite la imagen? ¿La imagen despierta alguna emoción en el espectador (usuario)? ¿La imagen estimula algún estado mental en el usuario?

Palabras clave:

CARIÑOSOS.TRANQUILIDAD. DELICADEZA. ROMANCE.

Fuente: Elaborada por los autores.

\section{Segunda parte:}

Paso 3: Selección de usuario externo y aplicación de la Matriz 2.

Usuario 1: madre de un estudiante que pertenece al grupo.

Matriz 2: Segundo nivel del Modelo de Lectura para la Indización fotográfica basada en el Método Complejo y las Funciones Primarias de La Imagen

\section{Función informativa}

¿La imagen proporciona información sobre un hecho o evento en particular? ¿Cuál es este hecho o evento que se muestra en la imagen? ¿Qué muestran las imágenes?

Palabras -clave:

AMOR. AROMA. 


\section{Función comunicativa}

¿Qué comunica la imagen? ¿Qué mensaje transmite la imagen? ¿La imagen induce una acción? ¿La imagen instruye sobre un tema en particular? ¿La imagen ilustra una teoría? ¿La imagen ilustra algún objeto de manera realista?

Palabras -clave:

NATURALEZA PRESERVADA. TRANQUILIDAD. TERNURA. SIN MIEDO: "ES TAN TRANQUILO QUE PARECE QUE PIENSA QUE NADA PUEDE SUCEDER CON ÉL”.

\section{Función reflexiva}

¿La imagen expone algún pensamiento del autor (fotógrafo)? ¿Cuáles son los pensamientos expuestos por el autor de la imagen? ¿Cuál es la intención del autor de la imagen? ¿Cuál es el posible significado que el espectador (usuario) puede dar a la imagen? ¿Qué reflexiones puede proponer la imagen?

Palabras -clave:

"LA INTENCIÓN ES PASAR LA SENSACIÓN DE PAZ Y PUREZA DEL ANIMAL”. TRANQUILIDAD. REFLEXIÓN “MIRAS LA IMAGEN Y COMIENZAS A REFLEXIONAR SOBRE CÓMO PODEMOS MEJORAR CON OTRAS PERSONAS".

\section{Función emocional}

¿Qué emociones puede despertar la imagen? ¿Qué emoción transmite la imagen? ¿La imagen despierta alguna emoción en el espectador (usuario)? ¿La imagen estimula algún estado mental en el usuario?

Palabras clave:

ESTADO DE "REFLEXIÓN Y ENCANTADOR". AMOR. ALEGRÍA. EXTREMADAMENTE ENCANTADOR. PUREZA. CUIDADO DE ANIMALES PARA LA NATURALEZA.

Fuente: Elaborada por los autores.

\section{Tercera parte:}

Paso 4: Análisis grupal de la diferencia en la indización realizada por el grupo y el Usuario 1. En la indización realizada por el grupo de estudiantes, fue necesario buscar términos más específicos como el género, la especie y también dónde se fotografió la ardilla, ya que el objetivo era llegar al mayor número de usuarios, incluidos aquellos especializados en el tema, como Biología, mientras que el usuario externo solía indizar una ma- yor cantidad de palabras clave que designan sentimientos. Debido a la profunda investigación de la fotografía analizada por el grupo de estudiantes, se observó que utilizaron una gran cantidad de palabras clave. Como resultado, el trabajo de este grupo resultó en una indización más exhaustiva, mientras que el grupo de usuarios usó menos palabras clave y, a veces, no logró convertir las frases en palabras clave.

\section{Muestra 2}

Primera parte:

Paso 2: Muestra 2 - Grupo 2

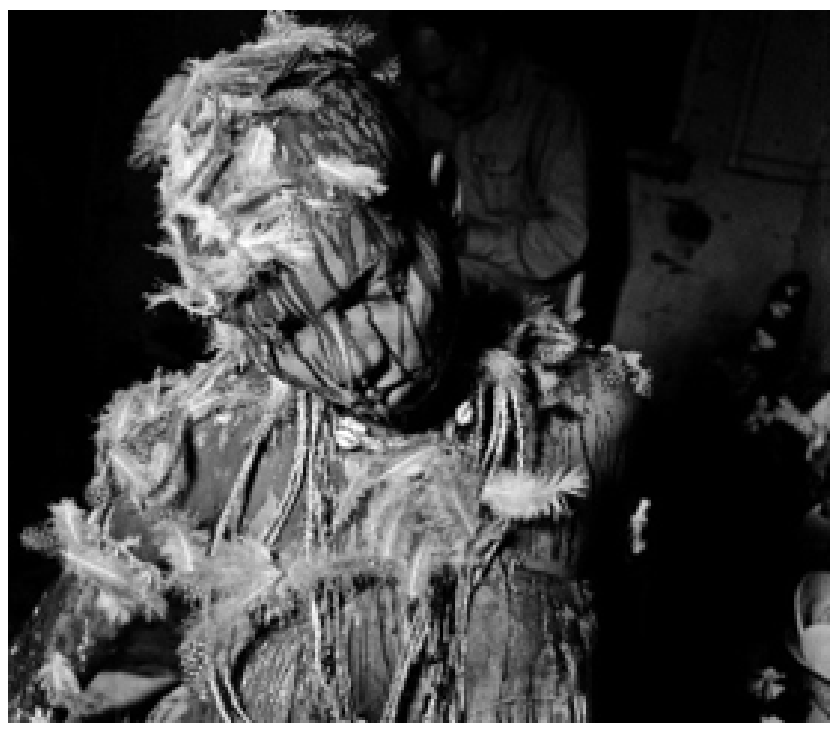

Fuente: IMS (2020)

\section{Paso 2: Aplicar Matriz 1 y Matriz 2 por Grupo 2.}

Matriz 1: Primer nivel del Modelo de Lectura para la Indización Fotográfica basada en el Método Complejo y Las Funciones Primarias de La Imagen

\section{¿De qué está compuesta la imagen?}

Descripción:

Autor: José Medeiros; Fecha: 1951; Técnica: matriz negativa. El autor tiene más fotos con el mismo tema que se publicaron en el artículo titulado "Las novias de los dioses sangrientos" de la revista "O Cruzeiro" y en un libro titulado "Candomblé" publicado en 1957. En algunos sitios web consultados, los comentarios que quedaron fueron elogios por la foto, en otros hubo un tono de crítica a la ética de la revista que inicialmente la publicó. 


\section{¿Que nutre la imagen?}

Descripción:

Los sitios Olhave, Ratchet Free y Revestrés Magazine utilizaron la fotografía para presentar la historia y el contexto en el que se realizó el ensayo, que resultó en fotografía, y por qué era tan importante en e se momento.

El sitio de la Enciclopedia Cultural Itaú usa la foto para presentar la biografía del autor.

El sitio web de Correio Nagô usa la foto para promover el lanzamiento de un libro que aborda la trayectoria del autor de la fotografía.

\section{¿A dónde va la imagen?}

Descripción:

Según el uso de los sitios mencionados, las posibles interpretaciones dadas por ellos son: Candomblé, Ritual Secreto, José Medeiros, Periodismo.

A partir de la búsqueda en el sitio Las palabras clave utilizadas en la indización fueron: Candomblé, Ensayo,

Fotografía, Fotoperiodismo, Georgia Quintas, IMS, Jose

Medeiros, Libro.

El sitio web de Free Ratchet utilizado para indexar las palabras clave: Candomblé, Foto, Fotoperiodismo.

Fuente: elaborada por los autores.

Matriz 2: Segundo nivel del Modelo de Lectura para la Indización Fotográfica basada en el Método Complejo y Las Funciones Primarias de La Imagen

\section{Función informativa}

¿La imagen proporciona información sobre un hecho o evento en particular? ¿Cuál es este hecho o evento que se muestra en la imagen? ¿Qué muestran las imágenes?

Palabras -clave:

RITUAL. RITUAL DE INICIACIÓN. MUJER. HIJA DE SANTO. TERREIRO DE OXÓSSI. SALVADOR. BAHIA. PLUMAS. SANGRE.

\section{Función comunicativa}

¿Qué comunica la imagen? ¿Qué mensaje transmite la imagen? ¿La imagen induce una acción? ¿La imagen instruye sobre un tema en particular? ¿La imagen ilustra una teoría? ¿La imagen ilustra algún objeto de manera realista?

Palabras -clave:

SACRIFICIO. RELIGIÓN. INICIACIÓN CANDOMBLÉ. CULTURA AFRICANA. CULTURA BRASILEÑA.

\section{Función reflexiva}

¿La imagen expone algún pensamiento del autor (fotógrafo)? ¿Cuáles son los pensamientos expuestos por el autor de la imagen? ¿Cuál es la intención del autor de la imagen? ¿Cuál es el posible significado que el espectador (usuario) puede dar a la imagen? ¿Qué reflexiones puede proponer la imagen?

Palabras- clave:

DESMITIFICACIÓN. RELIGIOSIDAD. TRADICIÓN CULTURA. AFRO-BRASILEÑA.

\section{Función Emocional}

¿Qué emociones puede despertar la imagen? ¿Qué emoción transmite la imagen? ¿La imagen despierta alguna emoción en el espectador (usuario)? ¿La imagen estimula algún estado mental en el usuario?

Palabras clave:

ENTREGA. DEVOCIÓN. CREER. FE.

Fuente: Elaborada por los autores.

\section{Segunda parte:}

Paso 3: Selección de usuario externo y aplicación Matriz 2.

\section{Usuario 2: vecino de un alumno del grupo.}

Matriz 2: segundo nivel del Modelo de Lectura para la Indización Fotográfica basada en el Método Complejo y Las Funciones Primarias de La Imagen

\section{Función informativa}

¿La imagen proporciona información sobre un hecho o evento en particular? ¿Cuál es este hecho o evento que se muestra en la imagen? ¿Qué muestran las imágenes?

Palabras- clave:

RITUAL DE FE. CUBIERTA DE SANGRE Y PLUMA. CABEZA RIESGADA.

\section{Función comunicativa}

¿Qué comunica la imagen? ¿Qué mensaje transmite la imagen? ¿La imagen induce una acción? ¿La imagen instruye sobre un tema en particular? ¿La imagen ilustra una teoría? ¿La imagen ilustra algún objeto de manera realista?

Palabras -clave:

CREER. RITUALES DE FE. DIVERSIDAD RELIGIOSA. ORACIÓN. OFERTA. SACRIFICIO DE ESPIRITISTA. 


\section{Función reflexiva}

¿La imagen expone algún pensamiento del autor (fotógrafo)? ¿Cuáles son los pensamientos expuestos por el autor de la imagen? ¿Cuál es la intención del autor de la imagen? ¿Cuál es el posible significado que el espectador (usuario) puede dar a la imagen? ¿Qué reflexiones puede proponer la imagen?

\section{Palabras -clave:}

ESPIRITUALIDAD. FE. RITUALES. DIVERSIDAD.

\section{Función emocional}

¿Qué emociones puede despertar la imagen? ¿Qué emoción transmite la imagen? ¿La imagen despierta alguna emoción en el espectador (usuario)? ¿La imagen estimula algún estado mental en el usuario?

Palabras- clave: CREER. FE. COMPASIÓN. EMPATÍA. DOLOR. PENITENCIA. TRISTEZA. SUFRIMIENTO. MIEDO. MAGIA. TRISTE.

Fuente: elaborada por los autores.

\section{Tercera parte:}

\section{Paso 4: análisis grupal de la diferencia en la indiza- ción realizada por el grupo y el Usuario 2.}

Se observó que tanto el grupo como el usuario identificaron palabras clave similares, como ritual, sacrificio y fe. Destacamos la diferencia en la información entre el uso de Matriz 1 y Matriz 2. En este caso, se observó el conocimiento de la información sobre el contexto de la foto, a través de una investigación realizada con la aplicación de Matriz 1 que permitió identificar la religión y que el ritual se evidenció en la fotografia, porque se realiza y donde se retrata. Mientras que el usuario externo describió solo lo que ve y siente con el análisis fotográfico. El grupo de estudiantes pudo indexar la fotografía de manera más completa y asertiva con la aplicación completa de ambos niveles de lectura.

\section{RESULTADOS}

Como resultado, se puede ver que el uso de la Matriz 1 utilizada en ambas muestras de investigación tenía como objetivo comprender el tema de las dos fotografías, lo que permitió al indexador ayudar a seleccionar palabras clave para indexar las fotos. Se observó que. al saber por qué se produjo la fotografía, es decir, al tener información sobre el contexto de producción, el profesional puede seleccionar mejor las palabras clave que van más allá de lo que se muestra y lo que se evidencia en la foto. Este conocimiento evita la mala interpretación y lo que no tiene nada que ver con el tema retratado.

A partir de esta suposición, la aplicación de la Matriz 1 en la Muestra 1, que corresponde a la fotografía del olor a flor de ardilla, permitió al primer grupo identificar información como el nombre del fotógrafo, identificar que se especializa en la vida animal y natural, certificar donde produjo la foto, detectando la especie de ardilla, comprobar que la foto se viralizó en Internet y trayendo reacciones positivas al público al parecer que la ardilla estaba enamorada de la flor amarilla, acercando la actitud del animal a la de un humano. El uso de la Matriz 1 hizo posible que los participantes de la investigación también identificaran que la ardilla olía a la flor y luego se alimentaba de ella por su característico animal. Esta información específicamente ayuda al profesional a reducir la visión romántica de la ardilla y también las expectativas positivas de la gente sobre el animal. El uso de la Matriz 2 nos permitió identificar palabras -clave usando Matriz 1 y de las preguntas de indización creadas para explorar las funciones primarias de la imagen. Es de destacar que estas palabras -clave pueden considerarse relevantes para una posible recuperación de las dos fotografías en un sistema de información. En cuanto a la Función informativa, obtuvimos palabras clave relacionadas con la especie de la ardilla, la ciudad de la foto, la estación del año.

Para retratar la Función comunicativa, se encontraron palabras -clave relacionadas con el mensaje que comunica la fotografía como armonía, delicadeza, suavidad, perfume, belleza. En esta muestra, se observó que la Función reflexiva es la más evidente porque el fotógrafo produjo en promedio 200 fotografías sobre el momento exacto y eligió algunas secuencias de la imagen para publicar en su Instagram, pero fue precisamente la foto em que la ardilla cerró los ojos (en realidad guiñando un ojo) transmitiendo la idea de que estaba suspirando, se volvió viral en Internet. 
La aplicación de Matriz 1 a la Muestra 2, que se compone de la fotografía ritual Candomblé, permitió al Grupo 2 identificar numerosas informaciones tales como que es un ritual secreto y fue capturado por primera vez, que es una producción en la que, inicialmente, se pretendía demostrar el carácter peyorativo de esta religión. También, a través del uso de Matriz 1 , fue posible analizar que este ritual secreto no es una macumba ni un ritual satánico, como muchos creen erróneamente y con prejuicios, sino una religión como cualquier otra.

A partir de la contextualización de la fotografía, utilizando Matriz 1 , fue posible identificar y registrar en Matriz 2 varias palabras -clave que se presentarán a continuación. En relación con la Función informativa, las palavras- clave se identificaron como aquellas relacionadas con el nombre del ritual y elementos descriptivos de la foto. Con respecto a la Función comunicativa de la imagen, se detectaron palabras -clave relacionadas con la cultura africana, la cultura y la religión brasileñas. Considerando la Función reflexiva de la Imagen, el Grupo 2 seleccionó palabras -clave que nos permiten reflexionar sobre el objetivo, y lo que está representado, como la desmitificación de la religión, tradición, religiosidad y cultura afrobrasileña.

\section{CONSIDERACIONES FINALES}

A partir de la aplicación del Modelo de Lectura para la Indización de Fotografías basado en el Método Complejo y las Funciones Primarias de la Imagen, se descubrió la importancia de comprender el contexto de la producción fotográfica. Este conocimiento fue posible gracias al uso de Matriz 1 para buscar elementos en fuentes de información confiables sobre la motivación para la producción de fotografías diferencia al interpretar y elegir palabras clave para representar las fotografías de la muestra. En este sentido, los grupos que buscaron información sobre las fotografías de muestra identificaron un mayor número de palabras clave pertinentes a las fotos, pudiendo llegar a una audiencia que puede ser formada tanto por personas legas como por una audiencia más especializada.

Por lo tanto, como resultado positivo de la investigación, se observó que el contexto de la producción fotográfica permitió al profesional, en ambas muestras trabajadas, ofrecer más palabras -clave que usuarios externos. En contraste, el usuario externo que no buscó información más allá de lo que era visible en la foto identifico solo lo que podía interpretar.

En conclusión, se considera importante que el profesional de la información, en el momento de la indización, busque información sobre las fotografías para conocer su contexto de producción, y esto es posible con el uso de Matriz 1 en el primer nivel del Modelo de Lectura para la Indización de Fotografías, que también ayuda con la información para usar Matriz 2, que corresponde al segundo nivel del Modelo de lectura de indización de fotos.

\section{REFERENCIAS}

» Abril, G. (2007). Análisis crítico de textos visuales: mirar lo que nos mira. Madrid: Sintesis.

» Catalá Domènech, J. (2011). A forma do real: introdução aos estudos visuais. São Paulo: Summus.

» Catalá Domènech, J., Costa, M. (2015). "Por um olhar complexo sobre a imagem.Intercom": Revista Brasileira de Ciências da Comunicação, 38,1, pp. 295-308.
» Silva, G. ; Dias, C. (2018). Modelo de leitura para indexação de fotografias baseado no método complexo e nas funções primárias da imagem (Dissertação de mestrado). Escola de Ciência da Informação, Universidade Federal de Minas gerais, Belo Horizonte, MG, Brasil. Recuperado de https://repositorio.ufmg.br/handle/1843/ECIP-B6VM9Y [Fecha de consulta: 18 de octubre 2017] 